\title{
El ciclo festivo de un bufón llamado Don Pablos
}

Como en buena parte de la obra de Quevedo, en El Buscón concurren importantes elementos populares y, en concreto, la vida de su pícaro participa de la literatura carnavalesca, como ha sido destacado en varias ocasiones ${ }^{1}$. Tal mezcla de picaresca y carnaval, sin embargo, no parece casual, sino que creemos que existe una estrecha relación entre estos ámbitos, y especialmente en lo que se refiere a sus personajes respectivos: el pícaro y el bufón.

Numerosos son los puntos de contacto que sugieren una línea directa de sucesión entre ellos ${ }^{2}$, y de los que nos limitaremos a señalar los más fundamentales. En primer lugar, en una sociedad obsesionada por la honra, estos dos personajes se definen por no poseerla, condición que no sólo no ocultan, sino de la que precisamente sacan un beneficio material. El propio Pablos, a pesar de la vergüenza que dice sentir, no encubre su infamia ni a su destinatario ni, por tanto, al lector. Ejemplo claro es también Lázaro de Tormes quien, olvidándose de la "negra honra", consigue llegar a "la cumbre de toda buena fortuna".

Por su parte, el bufón, como nos indica Covarrubias, es hombre "sin vergüenza y sin respeto" que "tiene licencia de decir lo que se le antojare, aunque es verdad que todas sus libertades las viene a pagar con que le maltratan de cien mil maneras y todo lo sufre por su gula y avaricia. Vemos pues que la "deshonra" proporciona, tanto al bufón como al pícaro, un beneficio material y, en el caso de este último, ese desentendimiento del honor le da una libertad y tranquilidad que le es muchas veces envidiada, como expresan los elogios de la vida picaresca que aparecen en diversas obras del XVII.

1 Especialmente E. Cros, Ideología y genética textual. El caso del "Buscón" (Madrid: Cupsa, 1980). Véase también A. EGIDO, "Retablo carnavalesco del Buscón don Pablos", Hispanic Review, XIVI (1978), pp. 173-192. Precisamente se trata de un artículo-reseña de un libro anterior de Cros.

2 "El mismo género picaresco puede ser considerado como epidesarrollo o nueva etapa de la literatura bufonesca que [...] amplía su campo de visión para ocuparse no ya del campo de la corte, sino de la sociedad entera". (F. MárQuez VillanuEva, "Planteamiento de la literatura del "loco" en España", Sin Nombre, 10 (1979-80), núm. 4, pp. 7-25; p. 24). 
También ambos sirven a un amo hacia el que manifiestan un humor crítico que desenmascara sus vicios y defectos. El bufón don Francesillo de Zúñiga en su Crónica ${ }^{3}$ no deja de motejar de judíos, hambrientos, avariciosos o egoístas a todos los nobles, e igualmente Lázaro descubre en sus amos esos y otros vicios; por ejemplo, la hipocresía y ruindad del clérigo de Maqueda, destapada en los "apartes" del pícaro.

Coinciden igualmente en la importancia que la infancia cobra en ambos personajes. En el caso del bufón conviene recordar la relación entre la locura y los niños, muy presente en la época, como nos indica el propio Francesillo con el refrán «los niños y los locos por tiempo son profetas", destacando así el don divino que ambos tienen de decir la verdad. Asimismo en el caso del pícaro la infancia juega un papel fundamental, hasta el punto de identificarse a menudo al niño y al pícaro, aunque éste haya alcanzado ya la edad adulta. Tal sería el caso de Lázaro que, a pesar de escribir desde la madurez, nos deja en la memoria, sobre todo, el tiempo de su niñez.

Tampoco le es ajena al pícaro la inocencia infantil, desveladora de la verdad. El mismo Lázaro delata cándidamente a su padrastro, pues "como niño, respondía y descubría cuanto sabía" (Tratado $10^{\circ}$ ), y Pablos a menudo esconde la verdad bajo una fórmula de ingenua ignorancia, y así nos revela la condición de bruja de su madre, al hablarnos de "no sé qué de un cabrón y volar" (I.1). Muchas veces, por tanto, la vida del pícaro puede definirse con la fórmula de la "inocente malicia" que usa Pablos al referirse al episodio de Poncio Pilato.

Reflejo de la importancia de la niñez en ambos personajes es también el uso del diminutivo en sus nombres, pues entre los bufones encontramos al citado Francesillo y a otros como Velazquillo o Davihuelo; y entre los pícaros a Lazarillo o Estebanillo. La aparición en el Quijote de Ginés de Pasamonte, galeote que ha escrito su vida por sus pulgares, y que se enfada de que le llamen "Ginesillo" (I.22), nos muestra claramente la identificación entre el pícaro y un nombre en diminutivo.

Por último, tampoco la autobiografía, tan novedosa en el Lazarillo, y rasgo esencial del género picaresco para muchos críticos, es ajena a los bufones. La encontramos con el mismo carácter de propio rebajamiento en las cartas-coloquio del médico-bufón Villalobos, que ya Lázaro Carreter señaló como cercanas a la forma autobiográfica del Lazarillo ${ }^{4}$. Asimismo

3 Francesillo DE ZÚÑIGA, Crónica burlesca del emperador Carlos $V$ (ed. de Diane Pamp) (Barcelona: Crítica, 1981).

* F. LÁZARO CARRETER, "La ficción autobiográfica en Lazarillo de Tormes", Litterae Hispaniae et Lusitaniae (München, 1968). 
está presente el "yo" autodenigrado en la Crónica de Francesillo, pues éste no deja de reconocerse judío y cobarde, entre otras indignidades. El paso fundamental del autor del Lazarillo sería idear un personaje ficticio como soporte de esa misma fórmula.

En el Buscón la relación entre carnaval y picaresca resulta más explícita que en otras obras del género, por la importancia en esta novela del realismo grotesco 5 , así como por otros elementos que la vinculan con la literatura bufonesca. Entre estos últimos debemos considerar la presencia de una "premática" burlesca ${ }^{6}$, la cual pertenece a los géneros de disparates, pregones y pronósticos burlescos, etc., formas todas ellas cultivadas por los poetas-bufones - y también por Quevedo, quien no en vano es calificado de "Licenciado en bufonerías" en el libelo El Tribunal de la Justa Venganza (1635), escrito contra él- Igualmente tiene sentido dentro de la literatura bufonesca la importante presencia de la locura que prácticamente llena, a modo de leit-motiv, todo el Libro II, convertido en un auténtico desfile de dementes, como son el diestro o el arbitrista.

La utilización por parte de Quevedo de comparaciones burlescas, especialmente con el mundo animal, es propia también del realismo grotesco, y son habituales en el arte de motejar del que hacen gala los bufones. Así Pablos nos dice de la Guía que "parecía higo enharinado" (III.8), o que el licenciado Flechilla "parecía chirrión con sotana, pulpo graduado o mercader que cargaba para Italia" (III.2). Compárese con la fórmula tan usual en la Crónica de Francesillo: "parecía pato cocido o liebre empanado" (p. 73), o "parecía galgo que llevaban a caza por fuerza" (p. 72). Y, como sucedía en el caso del licenciado Flechilla, hay también una tendencia a la acumulación de comparaciones sobre un mismo sujeto: "parecía pastelajo de banquete enharinado o buey blanco en tierra de campos" (p. 70).

Pero sin duda lo que más claramente establece el acercamiento entre estos ámbitos es el hecho de que Quevedo elige, para la vida de su pícaro, una estructura organizada en torno a la fiesta popular. No se trata únicamente de las abundantes referencias cronológicas que remiten a fiestas populares a lo largo de toda la novela, como ha destacado $\operatorname{Cros}^{7}$; sino

5 Para el realismo grotesco es fundamental la obra de Mijail BAjTIN, La cultura popular en la Edad Media y el Renacimiento (Barcelona: Barral Editores, 1971).

6 Francisco DE Quevedo, La vida del Buscón (ed. de Fernando Cabo Aseguinolaza) (Barcelona: Crítica, 1993), pp. 118 y ss. Todas las citas del Buscón remiten a esta edición.

7 Cros encuentra estas referencias especialmente en la primera parte y establece un calendario festivo que iría del incidente de Poncio Pilato (Navidad) a las novatadas de Alcalá, que Cros relaciona con la Semana Santa, pasando por otros episodios como el de "rey de gallos" (Jueves gordo), y la estancia en casa de Cabra (Cuaresma). 
que Pablos parece recorrer en su vida un largo año, con sus tres ciclos festivos.

En el año, siguiendo la clasificación que hace Caro Baroja en su obra sobre el carnaval, se distinguen tres ciclos en torno a los cuales se organizan todas las fiestas populares: Cuaresma, Carnaval y Fiestas de Verano ${ }^{8}$. Cada uno de estos tres ciclos se ve caracterizado por un elemento básico. La Cuaresma se define por la abstinencia, mientras que el Carnaval, al contrario, por el banquete y cierto desenfreno, no solo alimenticio. A su vez, lo propio de las Fiestas de Verano es el amor, relacionado evidentemente, con la fecundidad.

El Buscón se organiza en tres libros en cada uno de los cuales se nos muestra un elemento destacado que coincide con el de cada uno de los ciclos festivos. Es evidente que en el Libro I resalta, sobre todo lo demás, la estancia en casa del licenciado Cabra, caracterizada por un hambre hiperbólica. Y por si cupiese duda de la conexión de este libro con el ciclo cuaresmal, Quevedo hace concurrir la entrada en el pupilaje con el "primero domingo después de Cuaresma", y la salida, con la llegada de otra Cuaresma 9. De esta forma, no pasan los muchachos en casa de Cabra ninguna Cuaresma, precisamente porque en casa del "licenciado Vigilia" todo el año lo es.

El primer libro se define, pues, por el ciclo de la Cuaresma, marcada por el hambre. Pero el hambre es, a su vez, destacada varias veces a lo largo de esas mismas páginas como ligada estrechamente a la vida de estudiante ${ }^{10}$, por lo que podemos también relacionar este primera parte - como también hace Cros- con la educación y, consecuentemente, con la infancia de nuestro personaje.

Tal correlación entre este primer libro y la Cuaresma no significa que no existan episodios de menor entidad vinculados con otros ciclos festi-

8 J. CARo BARoja, El Carnaval (Madrid: Taurus, 1983, 2. ${ }^{a}$ edición). Tras la época de Cuaresma y Semana Santa vuelve a haber una serie de fiestas jocundas en las que el aspecto amoroso parece triunfar sobre otros de sensualidad distinta: Mayas, san Juan, etc., de esta forma en el calendario el dominio de la Carnalidad y de todas sus secuelas es seguido por el de la Abstinencia, y después viene el Amor. (Parte I, Capítulo 9).

9 "Pasamos en este trabajo hasta la Cuaresma. Vino y, a la entrada della, estuvo malo un compañero" (pp. 75 y 76). Tal compañero moriría y éste será el motivo de que el padre de don Diego los saque de casa de Cabra.

10 Cuando a la llegada a Alcalá don Diego paga la patente, los que son ya sus compañeros lo celebran diciendo: "Pueda tener sarna, andar manchado y padecer la bambre que todos" (p. 85). Asimismo, al preguntar don Diego a Pablos qué hará si la justicia pregunta por los cochinos desaparecidos, le responde: "me llamaría a hambre, que es el sagrado de los estudiantes" (p. 93). 
vos, que aparecen y sirven de contraste al suceso central, a la vez que nos presentan la importancia de la fiesta popular en la evolución de Pablos, como personaje bufonesco que es. Muestra clara son los episodios de Poncio de Aguirre o del de "rey de gallos" (I.2) que reflejan la inocencia infantil que también es característica de este primer libro - y que ya hemos relacionado con el bufón-. También es el caso del auténtico mardi gras de la matanza de los cochinos intrusos en Alcalá, acontecimiento que sirve de transición al Libro II, pues marca precisamente el paso de Pablos de la inocencia de este primer Libro a la malicia que va a caracterizar el siguiente.

$\mathrm{Y}$ este Libro II tiene a su vez un centro fundamental que es totalmente contrario al del anterior. Se trata del banquete grotesco que tiene lugar en casa de Alonso Ramplón (II.4), banquete que nos lleva directamente a la noción de carnalidad y al ciclo del Carnaval. Quevedo da un paso más, pues no se limita a carne animal, como sí sucedía en Alcalá, donde también jugaba con la idea de que lo comido - las tripas- sea precisamente lo que come; sino que se trata de carne humana, y el banquete en casa de Ramplón adquiere, además, caracteres de comida totémica.

La comida totémica ${ }^{11}$ es un ritual en el que el alimento es precisamente el animal al que, salvo en esta ocasión, el grupo adora y respeta, hasta el punto de poder costar la vida a quien infrinja el tabú que a él se refiere. Se supone que de este modo se conmemora el asesinato del padre por parte de sus hijos, lo cual tendría lugar en la horda primitiva en la que el padre ejercía un dominio tiránico, especialmente en lo referente a reservarse para sí a todas las hembras. Los hermanos lo asesinarían y devorarían, absorbiendo así su poder. Los posteriores remordimientos, o el temor a una lucha fraterna ante la ausencia de una autoridad superior, les llevaría a sustituir al padre por un símbolo, en este caso un animal, con el que lo identificarían y al que respetarían como si se tratara de él mismo.

La comida totémica recuerda, por tanto, un acto de violencia originario que supuso la emancipación de la tiranía del padre, pero, por otra parte, expresa también la solidaridad de los hermanos en tal acto y, consecuentemente, participar de ella implica aceptar la pertenencia al grupo y ser aceptado por éste.

En el caso del banquete en casa del tío de Pablos se aprecian caracteres de comida totémica por cuanto la muerte del padre es producida

11 Una exposición de la teoría de la comida totémica se encuentra en S. FREUD, Tótem y Tabú (Madrid: Alianza, 1967). Especialmente el capítulo IV y, dentro de éste, el resumen que hace Freud de las ideas de W. Robertson Smith en el apartado IV y ss. 
por un miembro de su familia, en este caso, su propio hermano, y se da su posterior deglución por parte de un grupo ${ }^{12}$. Asimismo para Pablos supone liberarse del poder paterno, pues es a partir de ahora cuando puede intentar acceder a otro estamento y "negar la sangre. Precisamente por eso, porque no quiere entrar a formar parte del grupo que representaba su padre, pero también ahora su tío, es por lo que no participa del banquete, negando así su pertenencia al clan o, si se me permite la broma, al "tótem del gato" ${ }^{13}$.

Este segundo libro se relaciona con el ciclo del carnaval, por la presencia de este fundamental banquete grotesco que adquiere caracteres de comida totémica y, por tanto, de rito de iniciación que, en el caso de Pablos, y dada su negativa a participar en él, nos lleva a su emancipación y a considerar como edad para esta segunda parte del Buscón, la adolescencia.

Por otro lado, dentro de la noción de carnalidad que representa este segundo libro, la locura cobra un papel aún más importante, con ese desfile de "dementes" que Pablos encuentra en el camino. Como nos dice Caro Baroja, "la carnalidad implica no sólo realizar actos opuestos al espíritu cristiano, sino también actos irracionales, locos" ${ }^{14}$.

Por último, el tercer libro se caracteriza por el intento ascensional de Pablos a través de un matrimonio ventajoso. El elemento fundamental es por tanto el "amor", no sólo por ese intento, sino porque los galanteos se suceden, con la posadera (III.5), la cómica (III.9) o la monja (III.9), para

12 Aunque no sea propiamente la carne del padre de Pablos, se relaciona con ella, como sugiere Alonso Ramplón en su recordatorio a Pablos tras rezar por el alma del difunto: "Ya os acordáis, sobrino, lo que os escribí de vuestro padre». En cualquier caso, en la comida totémica no es la carne del padre la que se come, sino la del animal que le representa y, en este caso, la carne de cualquier otro ladrón ajusticiado es válida para simbolizar al padre de Pablos.

13 Varias son las veces en que de una u otra manera el padre de Pablos es llamado "gato", es decir, ladrón. Por otra parte esta interpretación del banquete grotesco en casa de Ramplón no entra en contradicción con quienes ven en él una parodia de la Sagrada Cena pues, al fin y al cabo, la historia de Jesucristo repite el mito universal del asesinato del padre que aparece en diversas culturas. Evidentemente Jesús simboliza al padre que es asesinado por sus hijos y, en concreto, por un miembro de la "familia" muy cercano a él, como es Judas. Posteriormente se instituye una comida en la que un alimento -el pan y el vino- simbolizan el cuerpo de Cristo y recuerdan a la vez el acto de violencia y nuestra comunión con él. Sin embargo, prefiero referirme a la comida totémica porque ésta explica además el hecho de la emancipación de Pablos y porque se relaciona mejor, como luego veremos, con la segunda comida totémica, que tiene lugar al final de la obra.

14 Op. cit., I.3. 
acabar finalmente, tras el fracaso de todos ellos, y especialmente del intento matrimonial con la prima de don Diego, en una unión amorosa de índole muy distinta a la que buscaba en un principio; esto es, con la prostituta la Grajal (III.10).

La relación de este libro con el amor nos lleva ya a la madurez o edad adulta de Pablos.

Si la novela se estructura siguiendo los ciclos de la fiesta popular, no nos ha de extrañar que el personaje que se mueve por ella se conciba con los caracteres propios de su figura típica: el bufón. Pablos funciona en la obra como el personaje mítico que en muchas fiestas vive todo un ciclo vital, con unas determinadas vicisitudes, que acaban en su muerte $\mathrm{y}$, a menudo, en su posterior resurrección.

Pablos o, mejor aún, don Pablos, se reviste a menudo de los atributos del bufón, en el cual se dan precisamente esas ínfulas nobiliarias, evidentemente burlescas, que también caracterizan a nuestro pícaro. Tal presunción forma parte del juego bufonesco de la "rueda", del trocar lo alto por lo bajo y viceversa; disfrazarse de rey para así ridiculizarle. En esta línea debemos entender los "pensamientos de caballero" de Pablos, es decir, como medio de crítica y denigración, no sólo del propio Pablos sino, sobre todo, del grupo al que Pablos aspira a pertenecer. A través de Pablos podemos ver reflejado el resto de la sociedad, de la misma forma que el bufón era el espejo donde el amo podía ver su imagen invertida, su correlato burlesco en el mundo al revés.

Pablos resulta ser el reflejo burlesco de su amo don Diego, como prueba el hecho de que sus vidas transcurren paralelas a lo largo del Libro I: la mutua hambre pasada en casa de Cabra y la misma recuperación posterior, o el análogo bautizo en Alcalá, a través del dinero en el caso de don Diego y de gargajos y excrementos en Pablos; o, por último, las cartas respectivas que ambos reciben y les llevan a volver a Segovia. Estas similitudes, que parecen terminar ahí, continuarán en el Libro III con la reaparición de don Diego y la doble paliza que recibe Pablos.

En este sentido, no es raro que Pablos sea converso como lo eran muchos de los bufones que, de esa forma, añadían un elemento más a su indignidad. Tampoco extraña que lo sea asimismo su amo ${ }^{15}$, pues pre-

15 Así se acepta una vez que se demuestra la filiación de la familia Coronel con el judío Abraen Seneor que tomó el nombre de Fernán Pérez Coronel en 1492, adquiriendo el linaje de los antiguos Coronel que habían caído en desgracia. Véase Carroll B. Johnson, "El Buscón: D. Pablos, D. Diego y D. Francisco», Hispanófila, LI (1974), pp. 126. También A. REDONDO, "Del personaje de don Diego a una nueva interpretación del Buscón", Actas del V Congreso Internacional de Hispanistas, II, Instituto de Estudios Ibéricos e Iberoamericanos (Université de Bordeaux III: Burdeos, 1977) pp. 699-711. 
cisamente las burlas fundamentales del bufón son las de equipararse a sus amos, no sólo fingiéndose ellos mismos nobles, sino rebajando también a aquéllos a sus condiciones indignas, fundamentalmente la referente a su sangre nueva. En la Crónica de Francesillo no dejamos de encontrar a cada momento a personajes nobles motejados de judíos, incluido el antiguo amo de don Francesillo, el duque de Béjar ${ }^{16}$.

Quevedo parece tener presente este ámbito bufonesco y cabe incluso que haya una referencia al mismo en el propio título - pues pudiera ser suyo el de la edición de 1626-, ya que la aparición del "don" junto al nombre de un personaje bajo no dejaría de recordar la costumbre de los bufones de usar de tal partícula. Así lo hacían don Juan de Austria, bufón de Felipe IV, o don Pascual de la Corte y Vinorre, loco famoso de la época, conocido como don Pascual y así citado en diversas obras, como en la Perinola del mismo Quevedo. El propio Francesillo disfrutaba incluso de un privilegio imperial para poder usar el "don", él y sus herederos.

También, dentro de la habitual tendencia barroca a innovar en las rotulaciones de obras, capítulos y partes, quizás Quevedo hubiera optado por no usar el término "pícaro", ya extendido desde Alemán, y elegir el de "buscón", entre las numerosas voces que servían para referirse a un personaje de esa clase, por su parecido fónico con «bufón”. De tal forma la paradójica unión de "buscón" y "don" en el título sugeriría que la obra se emparentaba con la literatura bufonesca y con la picaresca, como a su vez también sugiere la expresión "historia de la vida".

A estos datos debemos añadir que Pablos mantiene con don Diego una relación más parecida a la que se da entre un bufón y su amo que la existente entre criado y señor. Pablos apenas realiza servicio alguno que forme parte de esas labores, al margen de una alusión indirecta, durante la estancia en casa de Cabra, al decir "comían los amos primero, y servíamos los criados" (p. 68), o el hecho de que en Alcalá fuera a comprar al mercado. Este último acto tampoco desdice de un condición bufonesca, pues también Estebanillo tenía, cuando ejercía de bufón, tareas relacionadas con la "bucólica".

Por el contrario, a lo largo de la obra abundan las referencias a las funciones de diversión del servicio de Pablos, y a que por estas activida-

16 Don Alonso de Zúñiga "llevaba la cabeza desarmada; y la causa fue no hallar halmete donde meter las narices" (ed. citada, p. 86), y el propio duque de Béjar dice: "Y tengo las narices en la Costanilla de Valladolid" (p. 73). Decir de alguien que tiene largas narices era entonces una forma clara de motejarle de judío. A su vez, Francesillo se autodenominará "este coronista conde don Francés" (p. 142), o incluso aconsejará "...que nos juntemos los príncipes, y que con mano armada castiguemos al Turco..." (p. 143). 
des es apreciado por don Diego y sus padres. Desde que se inicia la relación entre ambos muchachos vemos que Pablos iba a "jugar" a su casa los días de "fiesta" (p. 60) y, aunque parece ser Pablos el que paga a don Diego con comida y objetos -inversión burlesca de lo que debería ser la relación entre bufón y amo-, Pablos, tras una enumeración, resume su servicio a don Diego con un "y entreteniale siempre" (p. 62). También los padres de don Diego le llevan a su casa a comer, cenar e incluso dormir "viendo cuanto le regocijaba mi compañía" (p. 62), y cuando Pablos decide abandonar su casa para servirle, lo hace con ugran gusto de los suyos por el que daba mi amistad al niño" (p. 66). Estamos pues dentro de un léxico del entretenimiento, la fiesta y el placer.

La primera vez que Pablos hace algo a petición de don Diego es llamar Poncio Pilato a un tal Poncio de Aguirre (p. 62), lo que lleva a cabo "por darle gusto a mi amigo". Tal expresión —usada también más adelante, como hemos comentado arriba- define muy bien el servicio de los bufones, que no en vano son llamados también hombres de placer. De hecho es la misma expresión que volveremos a encontrar como razón de ser de otra obra bufonesco-picaresca, el Estebanillo González, cuyo protagonista dice haber escrito su vida tan solo "por dar gusto a toda la nobleza" ("Prólogo al lector").

No se trata tanto de asistir a don Diego como de entretenerle y adarle guston, que es lo que el mismo Pablos nos dice, cuando determina quedarse "a servir a don Diego u, por mejor decir, en su compañía" (p. 66). Tal matización, aunque puede parecer burlesca, nos expresa la peculiaridad de su labor. De hecho Pablos se refiere a don Diego como "amigo" en varias ocasiones y, como luego veremos, no hay indicios que nos muestren una mala relación.

Las mismas "travesuras" realizadas por Pablos en Alcalá sólo pretenden entretener a don Diego y a sus compañeros. El robo de las espadas a la ronda no es, como resulta evidente, una hazaña realizada para satisfacer una necesidad material del pícaro, sino sólo para divertir y mostrar ingenio, cosas propias del bufón ${ }^{17}$. Estas travesuras, sobre todo en su vertiente de ingenio verbal, recuerdan anécdotas de bufones recogidas en diversas colecciones de apotegmas, como sucede en la respuesta de Pablos de "llamarse a hambre", como sagrado que es de los estudiantes, si la

17 “...como servidor de don Diego tratará a los jóvenes de la nobleza que al alabar su ingenio le hacen tomar conciencia de su propio valer, aunque es evidente, por mucho que se esfuerce en disimularlo, que desempeña para ellos el papel del bufón" (A. VILANOVA, "Quevedo y Erasmo en el Buscón", Quevedo in perspective (ed. de James Iffland) (Newark: Juan de la Cuesta-Hispanic Monographs, 1982), pp. 139-179; p. 159). 
justicia inquiriese acerca de los cochinos desaparecidos. Igualmente cabe entender las novatadas que sufre Pablos en Alcalá como las burlas de las que es objeto el bufón pues, tal y como le recuerda a Estebanillo un mayordomo, "esos son los postres de los bufones" ${ }^{18}$.

Todo esto nos conduce a una característica particular del bufón: su "dualidad", ya que si es capaz de hacer que se rían de él, también él se ríe de todos, y es tanto sujeto como objeto de burlas. Si Estebanillo arranca las muelas de un judío en una pesada burla (II.94), también en otra ocasión poco falta para que le arranquen a él lo que más precia de su persona (II.80ss). Y si se disfraza en una mascarada de carnaval para hacer reír a sus amos (cap. VIII), a su vez éstos le convertirán en un cornudo al disfrazarle, contra su voluntad, de un animal dotado de cornamenta, y así pasearle a vista de todos (cap. VII).

Tal dualidad del bufón entre lo activo y lo pasivo parece reflejar la unión en un mismo tipo de los caracteres del bufón propiamente dicho, en cuanto a ser sobre todo objeto de risa, y lo que luego será más característico del pícaro, principalmente sujeto de burlas. Las dos caras de una misma moneda, una moneda necesaria en una sociedad que se define con respecto a la honra y que, por lo mismo, necesita de figuras deshonradas que le sirvan de contrapeso.

La dualidad del bufón está establecida en la relación superior-inferior, ya que, siendo precisamente lo más "bajo" en la sociedad, juega a equipararse a lo más "alto", e igualmente tiende a rebajar todo con sus bromas, mediante la denigración burlesca ${ }^{19}$.

Pablos es también prueba de este desdoblamiento - ya hemos hablado cómo en Alcalá es primero objeto para después ser sujeto de burlas- el cual queda muy bien ejemplificado en el episodio de "rey de

18 Y el propio Estebanillo una vez salvado del intento de castración de que es objeto, le dirá a Su Alteza Serenísima: "estos son caprichos de los señores y pensión de los de mi arte" (Estebanillo González (ed. de A. Carreira y J. A. Cid) (Madrid: Cátedra, 1990). II. Cap. 7). Por otra parte tampoco es contradictoria la relación con Cristo, pues conocido es que el episodio al que parece referirse Pablos al decir que no es "Ecce homo", es la parábola en la que Cristo aparece como un bufón, esto es, disfrazado de rey para ser así injuriado y posteriormente asesinado.

19 Francesillo de Zúñiga llega incluso a denigrar a la propia emperatriz mediante las fórmulas habituales del realismo grotesco: la ureina cayó en un charco, y la marquesa quedó colgada un pie en la angarillan (ed. citada, p. 110). También el emperador, aunque no cae en un charco, en un momento en que dos cortesanos se pelean por llevarle las faldas, cae al suelo revuelto con ellos (p. 141). Francesillo dirige una carta a la emperatriz en la que dice no haberla visitado "porque cuando mis amigos no están en casa no acostumbro a ver a sus mujeres, y así querría que hicieran mis amigos conmigo" (p. 172). 
gallos" en el que Pablos, como es propio del bufón, se disfraza de rey burlesco para ser así denigrado en la forma habitual del realismo grotesco; con la caída de lo alto a lo bajo, en este caso desde la altura del caballo a la bajeza de lodo. Pero en este episodio podemos encontrar en Pablos ambas facetas, la de rey de gallos y la de... gallo.

En esta fiesta se trata de matar un gallo y entre las formas que existen de hacerlo, una es precisamente anaranjearlo ${ }^{20}$, es decir, arrojarle naranjas. De tal forma, Pablos como rey de gallos, es desenmascarado por las berceras, en este caso representantes populares de la verdad, y recibe el castigo reservado a este ave, pues es objeto de un bombardeo de diversas verduras. $\mathrm{Y}$ para remarcar ese paso de rey de gallos a gallo, el propio Pablos, una vez caído en el lodo, se acepta a sí mismo como tal, al reconocerse lleno de plumas: “Hermanas, aunque llevo plumas no soy Aldonza de san Pedro, mi madre" (p. 65).

Claro está que también entra en juego aquí, como indica $\operatorname{Cros}^{21}$, una referencia a las brujas penadas por el Santo Oficio, como de forma inversa sucede en el Libro III, donde ante la idea de ver emplumada a la Guía, Pablos piensa levantarse "a tiempo que le tirase mi naranja" (p. 205) ${ }^{22}$. Tal relación es evidente por cuanto el gallo se asocia a espíritus malignos y su muerte es una manera de exorcismo. Pero el gallo también simboliza la carnalidad y la lujuria y, por tanto, este episodio tiene aún otra lectura, en la forma de batalla entre don Carnal y doña Cuares$\mathrm{ma}$, pues las berceras, representantes de ésta última, destronan con alimentos propios de ésta época al representante de la carne, indicando así

20 J. CARO BAROJA, op. cit., I.4. El gallo de carnestolendas era una fiesta que organizaban los propios maestros; se elegía a suertes un "rey de gallos" al que se engalanaba y salía a cabeza de los demás, y anaranjeaban o mataban un gallo con un instrumento punzante. Otra manifestación es la "corrida de gallos".

${ }^{21}$ Op. cit.: "Pablos/rey de gallos" no hace más que prefigurar la imagen del sentenciado, montado en un asno y azotado por el verdugo que lógicamente vendrá a ser (p. 33). Sin embargo, Cros olvida que Pablos no será nunca castigado de esa manera, y que más bien lo que refleja el episodio es esa dualidad de la que hablamos, sin que ello quite las concomitancias, por mutua influencia, que existen entre las fiestas populares y el desfile de sentenciados que nota Cros y que, lógicamente, también Quevedo utiliza.

22 Este es un claro ejemplo de la mutua influencia entre la fiesta popular y el desfile de supliciados. El último editor de la obra, Cabo Aseguinolaza, se extraña de que Pablos piense en arrojar a la Guía una naranja (p. 205, nota 48), y en nota adicional sugiere, para explicarlo, posibles sentidos amorosos del hecho de lanzar naranjas, o un significado hechicheril de esta fruta. Sin embargo, me parece que Pablos vuelve a jugar con la relación entre la bruja emplumada y la fiesta de gallos. 
el inicio del período de abstinencia que efectivamente va a comenzar en el capítulo siguiente, con la entrada en casa del licenciado Cabra.

El episodio nos muestra en Pablos esa doble cara bufonesca que une lo alto y lo bajo, y a la vez sirve de anuncio de lo que va a ser su historia; un continuo disfrazarse de rey, pero sólo para ser denigrado a través de caídas y golpes ${ }^{23}$. Se trata pues de una insinuación de su destino.

$Y$ ese destino se cumple definitivamente en el castigo que por orden de don Diego sufre Pablos en el Libro III. Aquí encontramos la misma dualidad ya que Pablos recibe dos palizas, una de las cuales va dirigida a él, como pícaro-bufón, mientras la otra va destinada al "rey" que representa, en este caso don Diego, del cual se disfraza vistiendo su capa. Se cierra de esta forma el círculo abierto en el episodio del "rey de gallos", ya que a partir de este momento Pablos renace hecho, ya sí, un auténtico pícaro que ha renunciado para siempre a sus aspiraciones bufonescas de ser caballero ${ }^{24}$.

Don Diego, en cambio, no parece renacer de estos golpes simbólicos, recibidos no por un asunto muy digno, sino por una "mujercilla". El antiguo amo de Pablos se nos ha descubierto tan pícaro como éste, igual que su prima ha resultado muy poco noble en su actitud para con el supuesto Felipe Tristán. Similar es el comportamiento que Francesillo achaca a ciertos señores, capaces de rebajarse con ocasión de conseguir alguna dádiva; es decir, como los propios bufones ${ }^{25}$.

23 En el Libro III cada vez que se finge otro acaba por los suelos, así cuando se hace pasar por rico para conquistar a la posadera, intenta llegar a su estancia por el tejado y acaba cayendo en casa del escribano; e igual sucede con la tan citada caída del caballo cuando pasea ante la casa de la prima de don Diego. En estos dos casos encontramos no solo la caída, sino otros elementos denigratorios tradicionales como son los golpes que recibe del escribano, o el caer en un charco que es, en definitiva, caer en el excremento y que es forma fundamental de denigración del realismo grotesco. Tal hecho lo encontramos en otros episodios en que se mancha a Pablos de sustancias fisiológicas (novatadas de Alcalá) o también a otros personajes como al avaro de la venta de Viveros que ve cambiado su alimento por excremento, inversión denigrante también habitual en el realismo grotesco.

24 Precisamente Angel G. LOUReIRo en su "Reivindicación de Pablos", RFE, LXVII (1987), pp. 225-244, basa su idea en este cambio, pues a partir de este momento, al olvidar sus pretensiones de caballero, ya no tiene por qué sentir vergüenza y esto explica que pueda hablar de su origen y de sus padres de la forma en que lo hace. Resulta coherente su actitud y de esta forma sí puede conciliarse su deseo de honra en un momento de su existencia, con la posterior redacción de una autobiografía "testimonio inequívoco de la vileza e ignominia del supuesto autor; en contra de lo que piensan Francisco Rico (de quien son las palabras entrecomilladas) y otros autores.

25 „Fernando de Osorio [...] cada vez que había vacante de algún obispado y Su Majestad salía a misa, hacía más reverencia que el duque de Traeto» (ed. citada, p. 84). 
El motivo que lleva a don Diego a apalear a Pablos no parece ser, entonces, sólo el deseo de castigarle por fingirse lo que no es, o querer igualarse a él a través del matrimonio con su prima; sino que sospechamos que don Diego teme también que su antiguo criado acabe desenmascarándole. Tal idea viene sugerida por el contraste entre la opinión que de Pablos tiene ahora, pues se refiere a él como ael más ruin hombre y más mal inclinado tacaño del mundo", y la relación de ambos en el Libro I. Al margen de las pequeñas estafas que Pablos le hiciera en connivencia con el ama, y de las que don Diego no llegó a saber, no hubo nada entre ellos que pudiera llevar a tener esta opinión. De hecho hemos hablado de una relación próxima a la amistad y, sin olvidar lo que de posible ironía hubiera en tales referencias, no cabe duda de cierto afecto, pues es don Diego quien aconseja a Pablos que despierte "que asan carne" y, ante la necesaria despedida de ambos, quiere acomodarle con otro caballero.

La razón de esta violencia verbal y de la posterior violencia física cabría explicarla por el deseo de don Diego de distanciarse de Pablos ante el temor a verse desenmascarado por quien le conocía bien a él y a su origen. Prueba de esta preocupación de don Diego es el hecho de que cuando desaparece definitivamente, antes de la paliza, utiliza una expresión que Pablos ha repetido a lo largo de la obra: "me importa (...) que no me conozcan" (p. 200).

Al contrario que don Diego, Pablos renace, en un ya definitivo paso de la inocencia a la malicia, convertido esencialmente en pícaro, como prueba su asociación a los jaques sevillanos. Vuelve así a cerrarse otro círculo, pues si Pablos había logrado escapar de su padre y su tío, negándose a participar de la comida que lo identificaba como perteneciente a su clan ${ }^{26}$, ahora acaba entrando de lleno en otra comunidad que en realidad es la misma, la de los ladrones y asesinos. Por tanto, sí se integra ahora en otro banquete grotesco, que igualmente adquiere caracteres de comida totémica.

De nuevo tenemos un ladrón ejecutado, en honor del cual se come y bebe (p. 225), y nuevamente hay un crimen contra la autoridad, que en este caso no es la paterna, sino la civil, pero que implica igualmente, por parte de Pablos, la emancipación de cierta potestad o, lo que es lo mismo, la aceptación de vivir en desacuerdo y oposición con las normas que

También nos cuenta Francesillo que al saber Antonio de Fonseca que había muerto el comendador de Castilla, cayó a su vez muerto por espacio de una hora y al recobrarse dijo: "Santa María, ¡Si me proveerá el Emperador desta encomienda!" (p. 135). Muchas otras alusiones de este tipo se suceden en la Crónica.

26 Igualmente Pablos se niega a compartir otra comida de grupo, la sopa de los Jerónimos, sustento de don Toribio y sus compañeros (p. 161). 
tal autoridad impone. Ahora sí participa Pablos tanto del banquete como del asesinato de corchetes, llevado a cabo por los jaques a modo de un auténtico clan fraterno de pícaros y asesinos.

De esta forma Pablos, como pícaro-bufón, ha recorrido parte de la sociedad a través de los ciclos festivos del año que se han desarrollado paralelamente a su evolución personal, unida también a un descenso moral que a su vez coincide con un descenso geográfico desde Segovia a Sevilla, pasando por Alcalá, Madrid y Toledo. Todo un largo proceso que le ha conducido finalmente a sufrir la muerte simbólica, que ya se anunciaba en el episodio de "rey de gallos", arrastrando en ella a su amo. A pesar de sus deseos de no ser conocido, don Diego no puede dejar de desenmascararse, a ojos del lector, por la paliza simbólica que recibe vicariamente Pablos, que se ha vestido su capa para mostrar una vez más su naturaleza de bufón disfrazado de rey.

Pablos renace en los últimos capítulos convertido en un auténtico pícaro que olvida sus ínfulas nobiliarias, y acaba participando en la comida totémica que le identifica como perteneciente al grupo de los ladrones del que en un principio ha querido huir. Prueba de esta definitiva incorporación es que el enlace matrimonial que ambicionaba para acceder a otro estamento, se ha trocado burlescamente en la unión con una prostituta a la que acepta para toda la vida, o al menos, se propone "de navegar en ansias con la Grajal hasta morir" (p. 226).

Quevedo, pues, parece haber encontrado en el pícaro una figura cercana a la del bufón que, como tal, servía a sus ideas satíricas, usando de las formas del realismo grotesco - que utiliza en muchas de sus obras- y de los recursos y caracteres del bufón. Quizá Quevedo leyera de esta manera el propio Lazarillo, que se nos presenta como su principal modelo, pues es evidente la dependencia respecto a la obra anónima en aspectos fundamentales, especialmente en la creación de personajes, como el licenciado Cabra, clara hipérbole del clérigo de Maqueda, o también don Toribio, relacionado con el escudero, tercer amo de Lázaro. En la obra de 1554 encontraría Quevedo un personaje principalmente niño, lo que de por sí le acercaría al bufón, que, como éste, sirve a amos a los que critica y desenmascara a través de un humor crítico. Más aún, Quevedo pudo percibir como propio de la literatura bufonesca la equiparación burlesca final entre el pícaro y el emperador, cuando Lázaro hace coincidir su "cumbre de toda buena fortuna" con la entrada victoriosa del emperador en su misma ciudad. De esta forma el anónimo autor parece establecer un paralelo entre la vida de un personaje bajo y otro alto ${ }^{27}$, insinuando acaso que el

27 La misma idea la recoge también el autor del Estebanillo, que también tiene al Lazarillo como modelo muy importante. Así Estebanillo al finalizar su narración y 
éxito de Carlos $\mathrm{V}$ es debido también a ciertas indignidades - ¿amancebar a Castilla con el Imperio?-, y en cualquier caso mostrando al lector la paradoja del triunfo del rey de la sociedad llena de la miseria y mezquindad que ha sido reflejada a lo largo de toda la obra.

Quevedo, gracias a la aparición de otras novelas picarescas, y en especial el Guzmán, tomaría conciencia de un género, pero decidió volver sus ojos al modelo originario que se ajustaba mejor a sus ideas, y quizá también como una manera de oponerse a Alemán ${ }^{28}$. Tal vez incluso las últimas frases de Pablos, referentes a su ida a Indias, y el poco cambio que para su carácter eso significó, fueran un último dardo contra el propio Alemán quien intentaría en varias ocasiones partir para América, lo que logró en 1608. De esta forma Alemán, y otros que siguieran ese camino, aparecerían comparados con el pícaro converso que es Pablos al que, si finalmente no ha podido cambiar de estamento, le queda siempre la opción de seguir cambiando de lugar.

\section{VALENTÍN PÉREZ VENZALÁ}

La literatura picaresca y la bufonesca tienen importantes concomitancias, lo que ejemplifica claramente el Buscón de Quevedo. Esta obra se estructura en torno al calendario de la fiesta popular, y el personaje principal se caracteriza, a su vez, con los atributos del bufón.

Picaresque literature has elements in common with buffoonesque literature, as the 17th-century novel El Buscón, by Francisco de Quevedo, illustrates. The structure of this novel reflects that of the calendar of popular feasts and its main character has the attributes of the buffoon.

expresar su deseo de retirarse a su casa de juego en Nápoles, se compara con el Emperador retirado en Yuste.

28 Diversos autores coinciden en la idea de que Quevedo escribiría, entre otros motivos, por reacción a las ideas que expresa Alemán en su Guzmán. Así Lázaro Carreter: "Yo no hallo características picarescas en la obra de Quevedo que no puedan ser explicadas por el Guzmán o el Lazarillo. Don Francisco montó sobre ambas el entramado de su Buscón, pero en clara hostilidad contra Alemán, y apoyándose en la obra anónima como fórmula preferible. La vida de Pablos tiene todos los rasgos de una enérgica reacción contra aquella mezcla de épica y didáctica que el sevillano ofrecía" ("Para una revisión del concepto "novela picaresca" en Lazarillo de Tormes en la picaresca (Barcelona, 1972), pp. 193-224). 